\title{
Comparison of Aerosol Optical Depth Products from Multi-Satellites over Densely Populated Cities of Pakistan
}

\author{
Furqan Mahmud Butt ${ }^{1, a^{*}}$, Muhammad Imran Shahzad ${ }^{1, b}$, Seemab Khalid ${ }^{1, c}$, \\ Nadeem Iqbal ${ }^{1, d}$, Anjum Rasheed ${ }^{2, e}$, Ghulam Raza ${ }^{3, f}$
}

\section{${ }^{1}$ Earth \& Atmospheric Remote Sensing Lab (EARL), Department of Meteorology, COMSATS Institute of Information Technology (CIIT), Islamabad, Pakistan}

\author{
${ }^{2}$ Centre for Climate Research \& Development (CCRD), CIIT, Islamabad, Pakistan \\ ${ }^{3}$ National Institute of Laser and Optronics (NILOP), Islamabad, Pakistan \\ a*furqan.mahmud@comsats.edu.pk, ${ }^{\text {, }}$ imran.shahzad@connect.polyu.hk, \\ cseemabkhalid3@gmail.com, dengr.nadeem.iqbal@gmail.com, \\ eanjum.rashhed@comsats.edu.pk, 'newriver@gmail.com
}

Keywords: Aerosols; Air pollution; Environment; Aerosol Optical Depth (AOD); Remote sensing

\begin{abstract}
Air pollution in Pakistan is causing damage to health, environment and quality of life. Air pollution in Pakistan is not effectively monitored due to heavy cost involved in setting up ground stations. However, Satellite remote sensing can effectively monitor the air pollution in terms of Aerosol Optical Depth (AOD) at regional as well as global level. However, algorithms used to derive AOD from different sensors have some inherited differences which can pose challenges in monitoring regional AOD at high temporal resolution using more than one sensor. Therefore, this study focuses on comparison of four major satellite based AOD products namely Moderate Resolution Imaging SpectroRadiometer (MODIS), Multi-angle Imaging SpectroRadiometer (MISR), Ozone Monitoring Instrument multiwavelength (OMI) aerosol product and Cloud-Aerosol Lidar and Infrared Pathfinder Satellite Observation (CALIPSO) with the ground based AErosol RObotic NETwork (AERONET) AOD which is only available from Lahore and Karachi in Pakistan. The correlation of various AOD products with AERONET AOD is estimated statistically through coefficient of determination $\left(\mathrm{R}^{2}\right)$, Root Mean Square Error (RMSE), slope and intercept. It is noticed that MODIS is relatively accurate and reliable for monitoring air quality on operational bases over the land cover area of Lahore $\left(\mathrm{R}^{2}=0.78\right.$; RMSE $\left.=0.18\right)$, whereas MISR over the coastal areas of Karachi $\left(\mathrm{R}^{2}=0.82\right.$; RMSE $\left.=0.20\right)$. The results of the study will help the stakeholders in planning additional ground stations for operational monitoring of air quality at regional level.
\end{abstract}

\section{Introduction}

Suspended particles in air or atmosphere in solid or liquid form are known as Aerosols. Aerosols can have different sources, sizes, shapes and spatiotemporal distributions. It is important to study aerosols because they influence atmosphere/climate of the earth, atmosphere conditions and radiation budget as well as and eventually affects the human health. Recent studies have been in focus on the damage through fine aerosols to the respiratory systems of human beings [1,2]. Clouds and aerosols which are closely associated with each other, at the global level play an important role in the energy budget of the earth. Key elements in the formation of clouds are aerosols, because they serve as the condensation nuclei. Haze and dust are equivalent to aerosols traditionally. Historically, human observations for atmospheric visibility have been used to monitor atmospheric aerosols which later are replaced with ground based observation using air samplers. Such studies have proven their usefulness but has less effective in terms of aerial coverage and operational cost. However recent developments in the field of satellite and ground based remote sensing has opened new horizons to monitor air quality at regional bases cost effectively.

Globally, many studies have reported the ability of remote sensing technology to measure the continuous aerosol size distribution ranging from 0.01 to $10 \mu \mathrm{m}$ which can be produced from biomass burning, reactive gases and natural environment processes such as sea salt [3-9]. However, 
still there have been relatively few studies on effects of aerosols on air quality and climate of Pakistan [4-9]. Additionally, to the best of our knowledge very few studies have been conducted on optical properties of aerosols using remote sensing. These studies are reported for Lahore and Karachi due to availability of the only AERONET stations [10]. Studies have reported that Pakistan's major cities like Lahore and Karachi experience twenty times more air pollution as per standards of World Health Organization (WHO) [10]. Deteriorating air quality has forced residents of theses city to breath in unhealthy air more than 10 months per year [11]. Rapid urbanization and indiscriminate economic growth have led to imperceptible increase in aerosol loading over Pakistan. Unfortunately, there is insufficient infrastructure in Pakistan to monitor the rapidly increasing air pollution using traditional ground based sampling station. Pakistan has only two AErosol RObotic NEtwork (AERONET) ground stations to monitor AOD which are located in Lahore and Karachi. AERONET is a worldwide federation of ground-based, automated Sun photometers producing spectral AOD, aerosol microphysical properties, and precipitable water using standardized calibration, observation, cloud-clearing, data processing, and data distribution procedures $[12,13]$. However, satellite remote sensing can monitor the air pollution in terms of AOD at regional as well as global level using the algorithms based on global emission scenarios.

Different algorithms have been developed globally to retrieve AOD from satellite sensors over; water [14], vegetation, [15], bright surfaces such as deserts [16], and complex surfaces such as urban areas [17]. Although most of these algorithms are robust at global level but still, there remains uncertainty as to the prevailing optical and physical characteristics of urban aerosol experienced under each set of meteorological conditions [17]. Globally these AOD data are validated against ground based AERONET which is managed by NASA $[12,13]$. The accuracy of AERONET is \pm 0.02 once post calibrated (i.e., level 2.0) [18]. That is why the measure of the in-situ AOD is widely used to validate satellite based AOD products [19]. Such studies in Pakistan can play a crucial role in selecting a most appropriate sensor (algorithm) for Pakistan or any other region. Therefore, this study is designed to compare and validate major satellite based AOD products from MODIS, MISR, OMI and CALIPSO with ground based AOD from two AERONET stations at Lahore and Karachi. The results will suggest the most suitable satellite to monitor the aerosols condition over different land surfaces for urban areas of Pakistan. This paper provides a comprehensive analysis of aerosols' contribution towards air pollution in Pakistan.

\section{Data Used and Applied Research Methodology}

This study uses level 2.0 quality assured and cloud screened AERONET data from Lahore and Karachi stations for years 2006-2013. AERONET AOD level 2.0 data from NASA website was downloaded with in \pm 30 minutes of the satellite pass time for Lahore and Karachi stations [17] and compared with satellite based AOD extracted at 5x5 pixel (spatial) window over Lahore and Karachi's AERONET stations. This data was used to validate the satellite based AOD retrieved from MODIS, MISR, OMI and CALIPSO at spatial resolutions of $550 \mathrm{~nm}, 558 \mathrm{~nm}, 532 \mathrm{~nm}$ and $342 \mathrm{~nm}$ respectively (Table 1). MODIS is a sensor on board the TERRA and AQUA satellites that provides AOD products (MOD04 and MYD04) daily at $10 \mathrm{~km}^{2}$ spatial resolution [25]. MODIS Land and Ocean Best AOD was derived from Deep Blue and Dark Target algorithms [25]. MISR sensor was launched into polar Earth orbit aboard the Terra spacecraft in December 1999 to provide an AOD product (MISR_AM1_AS_AEROSOL) at spatial resolution of $17.1 \mathrm{~km}^{2}$ on every 17 days [26]. Another sensor OMI with advance viewing capabilities is an inheritor of instruments such as the Total Ozone Mapping Spectrometer (TOMS) and provides an AOD product OMI_Aura_L3_OMAEROe at a spatial resolution of $27.8 \mathrm{~km}^{2}[17]$. Unlike previous sensors, CALIPSO provides vertical profiles of aerosol loading as well along with spatial and optical properties of aerosols and clouds at footprint of $5 \mathrm{~km}^{2}$ in form of its AOD product (CAL_LID_L2_05kmAPro_Prov_V3) [27]. All AOD data is computed at or near $500 \mathrm{~nm}$ 
wavelength. Rigorous statistics of correlation, Root Mean Square Error (RMSE) and linear regression [28-31] is used to establish the accuracy of each product (Table 1).

Table 1. Summary of Data Sets with their product, spatial resolution and wavelength details.

\begin{tabular}{lllc}
\hline \multicolumn{1}{c}{ Source } & \multicolumn{1}{c}{ Product } & Spatial Resolution & $\begin{array}{c}\text { Wavelength } \\
\text { (nm) }\end{array}$ \\
\hline AERONET & Level 2 & Point data & 550 \\
MODIS & $\begin{array}{l}\text { MOD04/MYD04 } \\
\text { (Land and Ocean Best from Deep Blue } \\
\text { and Dark Target Algorithm) }\end{array}$ & $10 \mathrm{~km}$ & 550 \\
MISR & MISR_AM1_AS_AEROSOL & & 558 \\
CALIPSO & CAL_LID_L2_ & $17.6 \mathrm{~km}$ & 532 \\
OMI & OMI_Aura_L3_OMAEROe & $5 \mathrm{~km}$ & 342 \\
\hline
\end{tabular}

\section{Study Area}

There are only two AERONENT stations in Pakistan at Lahore and Karachi (Figure 1). Lahore $\left(31^{\circ} 32^{\prime} \mathrm{N} ; 74^{\circ} 22^{\prime} \mathrm{E}\right)$ is a thickly populated and the second largest city of Pakistan. It is situated near the Ravi River and covers an area of $1,772 \mathrm{~km}^{2}$ Lahore has a population of more than 10 million. Major industries situated near Lahore deal with iron, chemical, textile, automobile and construction materials. Climate of Lahore is hot semi-arid and wet as per the Köppen climate classification BSH. There are four main seasons with winter starting from November to February and spring season during March-April. Summer season (May-August) is hot and humid with frequent dust storms and followed by monsoon rains during July-August. There are high episodes of dust storms during this season. The onset of autumn from September through October is characterized by agricultural residue burning in the region at an extensive level. Aerosols over the city of Lahore are derived mainly from soil or road dust, industrial emissions and vehicular emissions or are secondary aerosols. Other anthropogenic sources include emissions from main highways, coal combustion and biomass burning [21]. High loading of aerosols in presence of cold and moist air during winter also creates frequent intense smog episodes in Lahore and other parts of central and northern Punjab.

Karachi $\left(24^{\circ} 51^{\prime} \mathrm{N} ; 67^{\circ} 02^{\prime} \mathrm{E}\right)$ is the largest and biggest industrial city of Pakistan. The climate of Karachi is characterized by dub-tropical maritime desert [22]. Three seasons exist in Karachi rainy and humid season which is extremely unpredictable and variable. It lasts from June to September. The average precipitation of the city is 7.75 inches. Sometimes of the year no rainfall occurs and sometimes exactly in the same season in the following year Karachi receives above average rainfall [20]. The winter season is very short lasting from middle of November to middle of February. Temperatures are mild and there is no frost. The rest of the months constitute the summer season. Rainfall in summer and winter seasons is negligible. The climate of Karachi, however, has some distinctive features because of the proximity to the sea. Sea breeze is a constant source of comfort throughout the year, except the winter months when the wind direction gets reversed. Relative humidity is also quite high except in winter season. Dew formation is quite common when the relative humidity is high and the differences in day and night temperatures are marked [23]. 


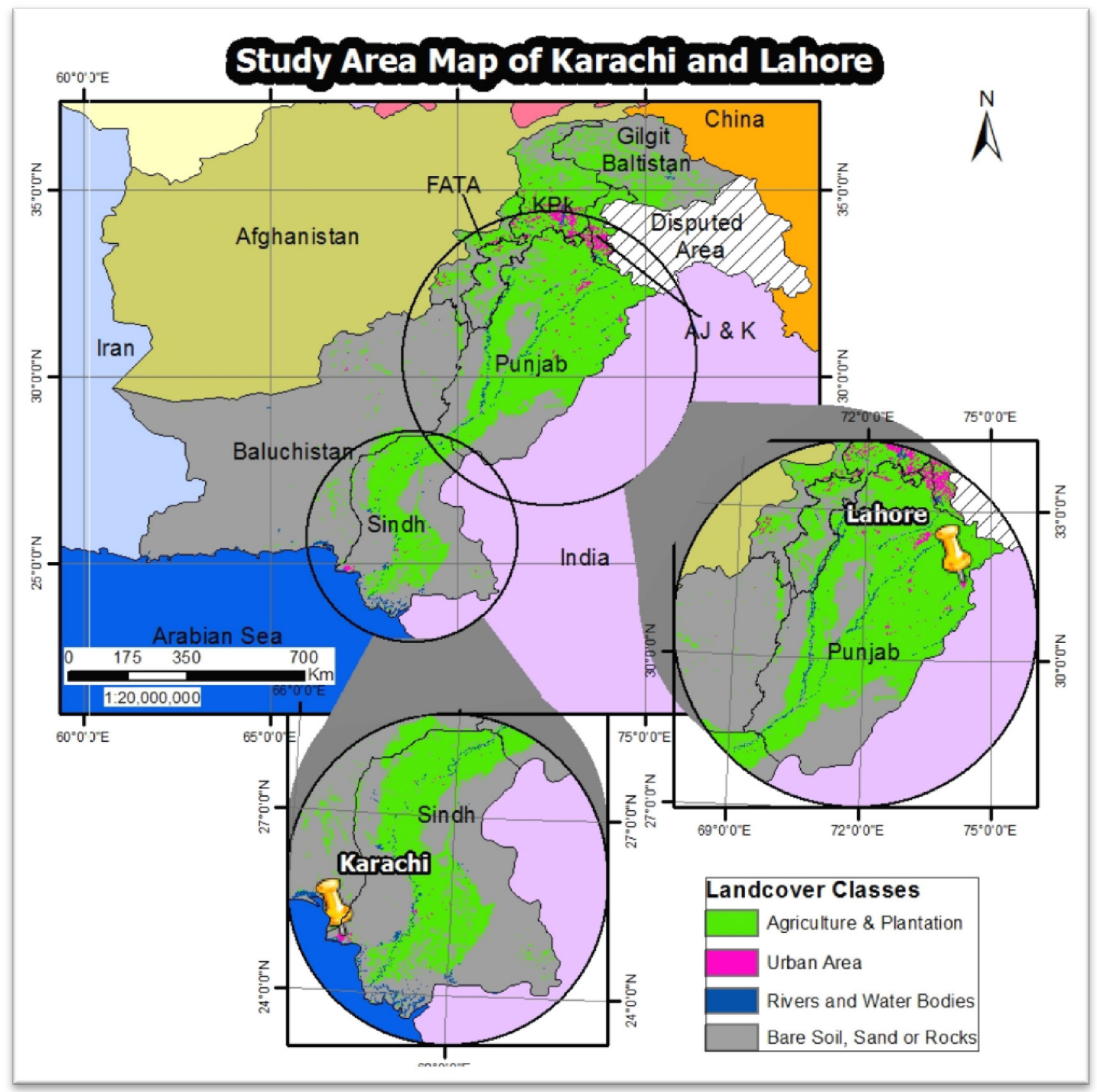

Figure 1. Locations of AERONET stations in the Study Area as reported by [24].

\section{Results and Discussion}

Overall, a very good correlations $(\mathrm{R}=0.78$ and 0.74$)$ with low RMSE of 0.18 and 0.20 have been observed between AODs from MODIS and AERONET over Lahore and Karachi respectively (Figs. 2a and 2e). As per previous studies reported for this region, estimated correlation in this study is noticed to be significantly improved compared [31, 32] which may be attributed to larger data size used for this study. MODIS data is highly correlated with the AERONET AOD for urban areas $\left(\mathrm{R}^{2}=0.78\right)$. However, a weaker correlation between MODIS and AERONET for coastal areas has been observed in this study and [33] as well because sampling spatial window of $5 \times 5$ pixel covers both bright surface of land and ocean. However, this is not the case for MODIS while retrieving AOD where each pixel is considered as either land or ocean.

Interestingly MISR AOD product performed better over coastal area than urban area with coefficient of determination of 0.74 and 0.82 and RMSE of 0.15 and 0.10 over Lahore and Karachi respectively (Figs. 2b and 2f) respectively. This may be due to AOD retrieval algorithm of MISR that uses larger number of aerosol models including aerosol mixture from different aerosol parameters than MODIS in addition to reported spatial resolution for its AOD product $[14,34,35]$. This increases the signal to noise ratio even for mix pixel. However, MISR seems to under estimate in highly polluted conditions which is the case for urban areas of Lahore.

OMI overestimates AOD with coefficient of determination of 0.69 and 0.64 over Lahore and Karachi respectively (Figs. $2 \mathrm{c} \& 2 \mathrm{~g}$ ) due to subpixel cloud interference since the large pixels can 
easily contain undetected cloud [36, 37]. CALIPSO reported relatively low correlation with AERONET data presenting $\mathrm{R}^{2}$ of 0.46 and 0.67 with RMSE of 0.24 and 0.16 over Lahore and Karachi respectively (Figs. $2 \mathrm{~d} \& 2 \mathrm{~h}$ ) which implies to the fact that it does not identify some thin layers of aerosols during daytime reducing signal to noise ratio. Although the AODs of these neglected layers is small, the cumulative AOD is significant. Another reason of weak correlation of CALIPSO AODs with AERONET is its limitation in data collection near surface during day light [38].

Lahore
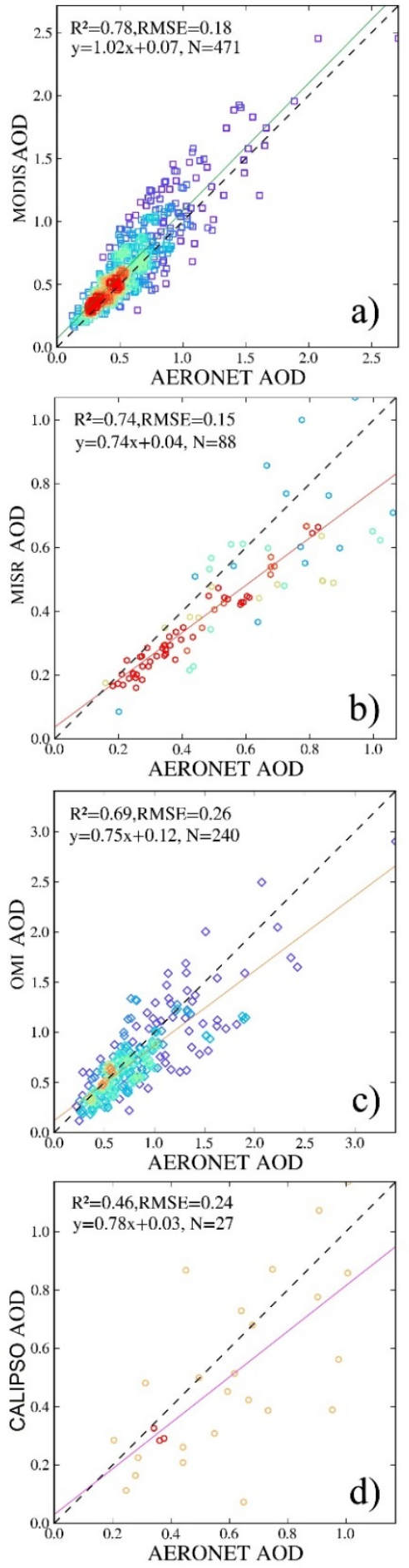
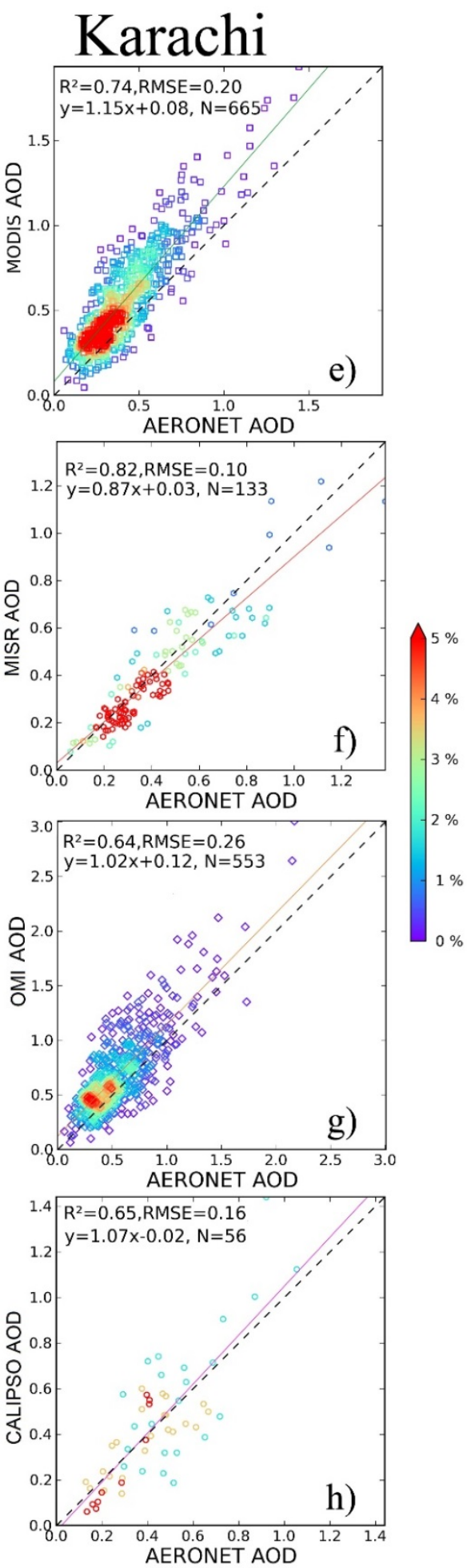

Figure 2. Overall data comparison of MODIS, MISR, OMI and CALIPSO AODs vs AERONET AODs over the cities of Lahore and Karachi from whole study period. In this figure the dash line indicates 1:1; solid line is the regression line and $\mathrm{N}$ is total number of observations. 


\section{Seasonal Comparison}

AOD products are also compared with AERONET AOD during different seasons to analyze seasonal variability over Lahore and Karachi (Figs. 3-6). Fig. 3 shows that during Fall season MODIS, MISR and OMI have significantly high correlations with AERONET data by $\mathrm{R}^{2}$ of 0.93 , $0.88,0.88$ and 0.32 respectively whereas, CALIPSO AOD is weakly correlated with AERONET for fall season as well. Overall high AOD has been observed over Lahore during Fall. Lahore experiences high aerosol concentration in Fall season due to agricultural residue burning in addition to local urban emissions. These emissions are confined to shallow inversion layer near to surface making a significantly turbid atmosphere. This gives rise to aerosol signal for most of the satellite except CALIPSO because CALIPSO has inherited limitation in recording near surface signal. MODIS and MISR AOD values for Karachi are highly correlated with AERONET with $\mathrm{R}^{2}$ of 0.69 \& 0.82 respectively, whereas a weak correlation has been observed for OMI and CALIPSO with coefficient of determination of 0.56 and 0.29 respectively (Figs. $3 \mathrm{e}-3 \mathrm{~h}$ ).

During winter season, MODIS, MISR, OMI and CALIPSO has shown higher correlations with $\mathrm{R}^{2}$ of $0.84,0.79,0.75$ and 0.91 for MODIS, MISR, OMI and CALIPSO respectively (Figs. 4a4d) over Lahore than Karachi (Figs. 4e-4h). Similar correlation of MODIS AOD and AERONET has been reported for winter season [39]. In winter season, Lahore faces mild fogy continental polluted winds from northwest but not in Karachi. Moreover, low temperature also lowers the planetary boundary layer increasing the concentration of near surface aerosols and hence density of lower aerosol column [40]. This increases the signal to noise ratio for satellite based sensors. Size distribution (not shown here) of aerosols from AERONET indicated that maximum AODs values in winter season are due to fine aerosol particle arising from emissions from industrial activities, transport and with space heating.

For spring season, high AOD values are observed over Karachi for all satellite sensor where MODIS, MISR, OMI and CALIPSO reported $\mathrm{R}^{2}$ of $0.71,0.73,0.47$ and 0.83 respectively (Figs. 5e5h). Although correlation of CALIPSO with AERONET is high for both Karachi and Lahore but more data is required to support this result. It has been observed that CALIPSO AOD has the highest correlation with AERONET data $\left(\mathrm{R}^{2}=0.94\right)$ for Lahore. However, MODIS, MISR and OMI products are less compatible with AERONET with $\mathrm{R}^{2}$ of 0.770 .73 and 0.55 respectively (Figs. 5a-5d).

During summer season, MODIS and OMI provided a better correlation with $\mathrm{R}^{2}$ of 0.75 and 0.73 respectively (Figs. 6a-6d) over Lahore, whereas, all satellite products except CALIPSO are well correlated with AERONET for Karachi with coefficient of determination of $0.75,0.69$ and 0.62 (Figs. 6e-6h). AOD has been observed to be high during summer season due to dust storms and high temperature leading to high aerosol particles [41]. In summer season, high temperature create low pressure areas in the south-west of Pakistan, in the northward and southward low pressure area create winds from Arabian Sea which are the main sources of sea salt [42, 43]. 

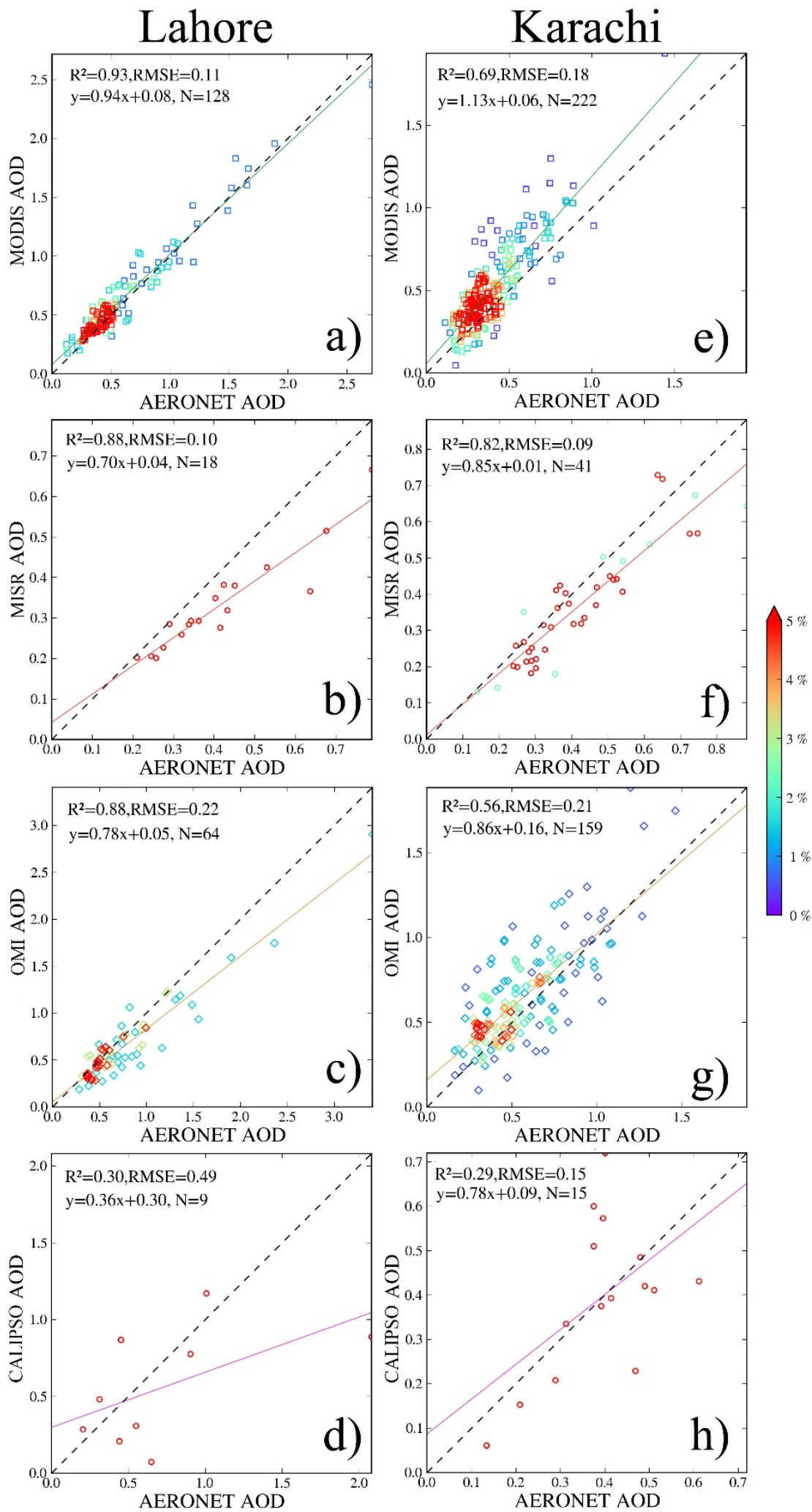

Figure 3. Fall season AODs variation of MODIS, MISR, OMI and CALIPSO AODs vs AERONET AODs over Lahore and Karachi. In this figure the dash line indicates 1:1; solid line is the regression line and $\mathrm{N}$ is total number of observations. 

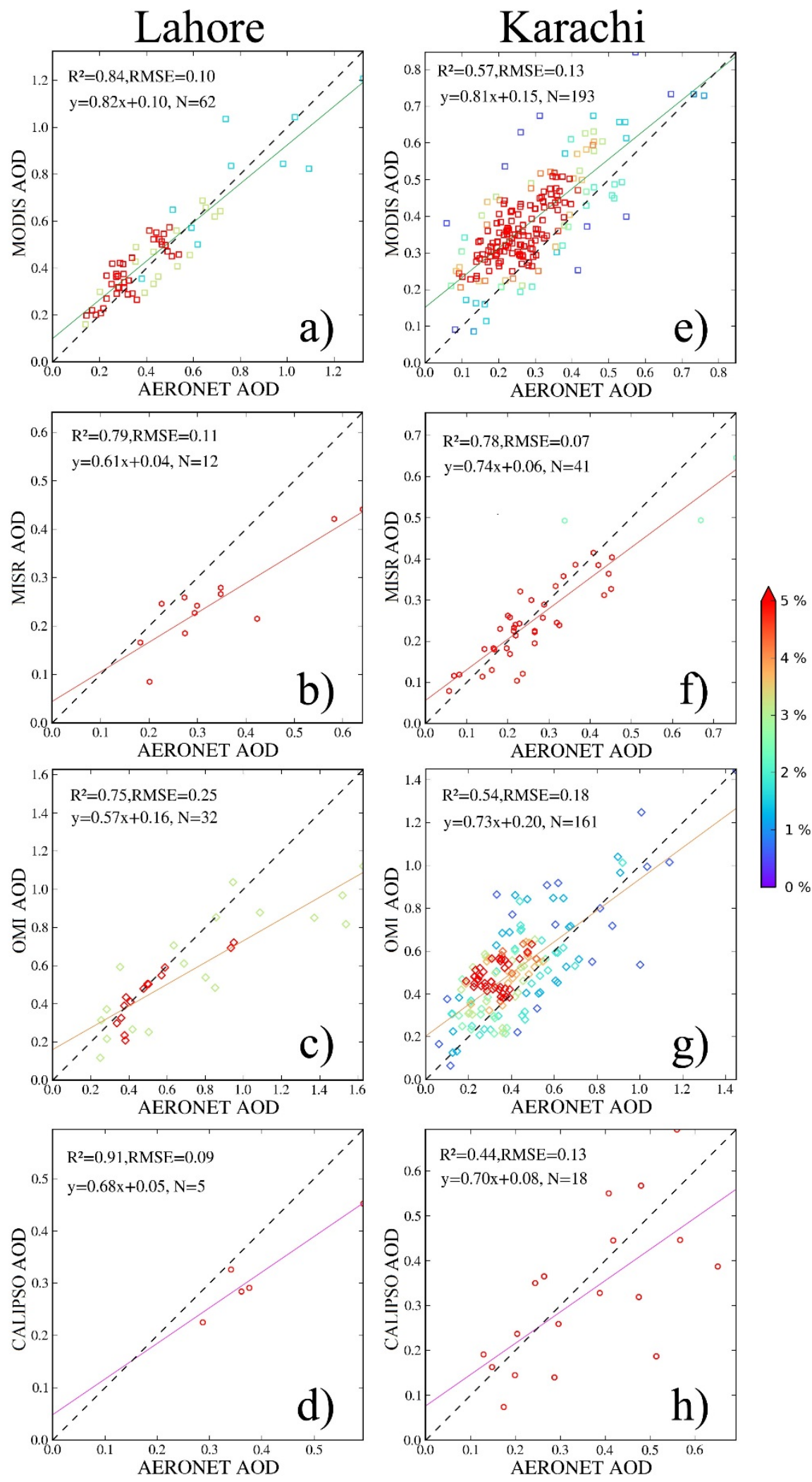

Figure 4. Winter season AODs variation of MODIS, MISR, OMI and CALIPSO AODs vs AERONET AODs over Lahore and Karachi. In this figure the dash line indicates 1:1; solid line is the regression line and $\mathrm{N}$ is total number of observations. 

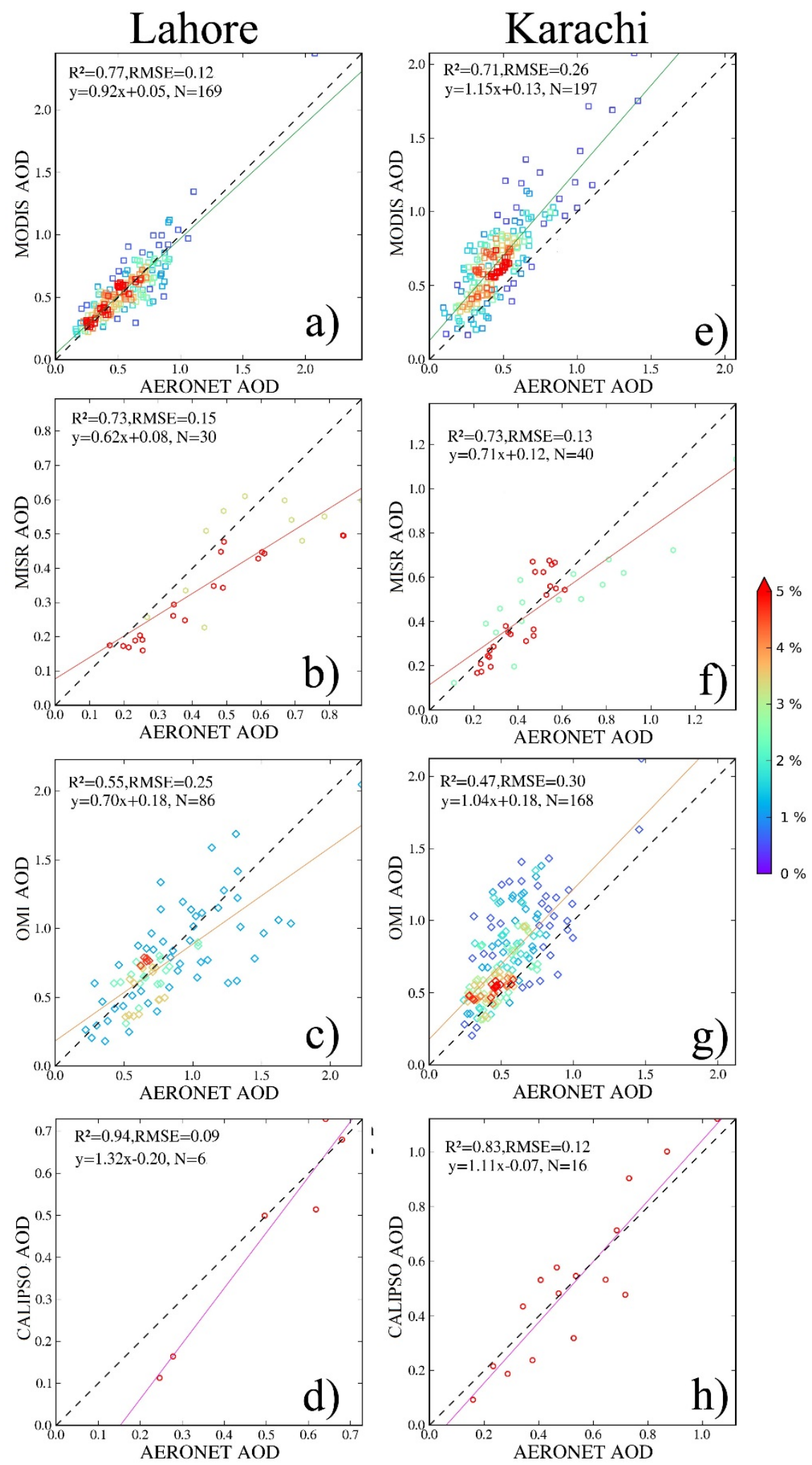

Figure 5. Spring season AODs variation of MODIS, MISR, OMI and CALIPSO AODs vs AERONET AODs over Lahore and Karachi. In this figure the dash line indicates 1:1; solid line is the regression line and $\mathrm{N}$ is total number of observations. 

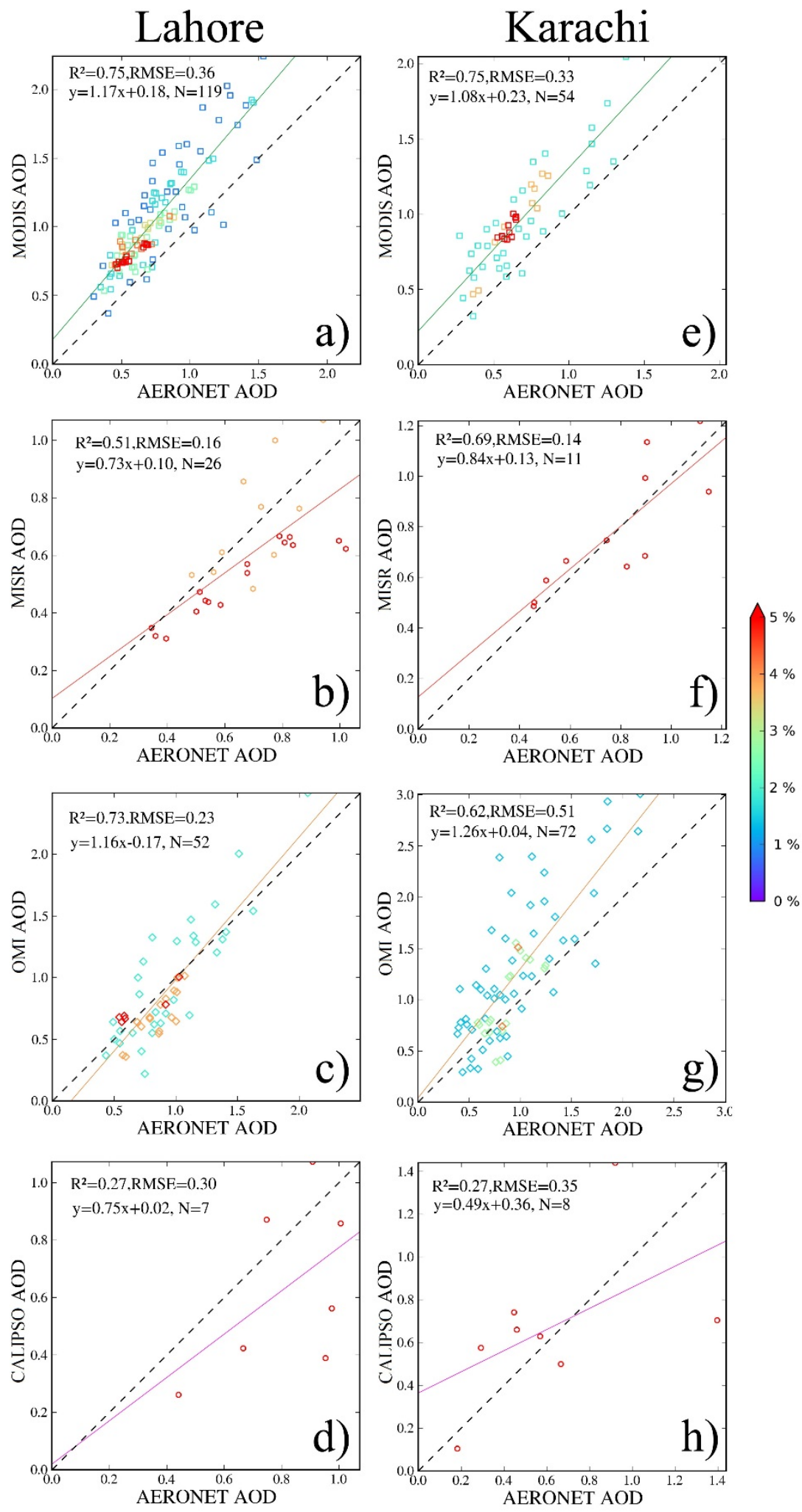

Figure 6. Summer season AODs variation of MODIS, MISR, OMI and CALIPSO AODs vs AERONET AODs over Lahore and Karachi. In this figure the dash line indicates 1:1; solid line is the regression line and $\mathrm{N}$ is total number of observations.

\section{Conclusions and Recommendations}

The purpose of the study was to validate the AODs values (derived from MODIS, MISR, OMI, CALIPSO) with ground based AERONET AODs. Overall, MODIS and MISR showed a good correlation with AERONET AODs. MODIS seems to be the most reliable satellite retrieved 
AOD for Lahore $\left(\mathrm{R}^{2}=0.78\right)$, whereas MISR AOD is more compatible to AERONET AOD for Karachi $\left(\mathrm{R}^{2}=0.82\right)$. The main source of high number of aerosols are industrial and vehicular emissions with sea salt particles from Arabian Sea to be an additional source for Karachi. In summer and fall seasons, the AOD values were maximum due to dominance of coarse dust particle, fine aerosol particle, sea salt aerosol particles due to high temperature. High AOD during Fall in Lahore is resulted by agricultural residue burning in Punjab, Pakistan with contribution of transboundary open fires in the same season. Maximum AOD values in winter season are due to fine aerosol particles being released from industrial and vehicular emissions and combustion for space heating. In addition, the meteorological conditions favor the formation of more nitrates. Lower temperature also leads to accumulation of aerosols in the area with slow dispersion. For accuracy assessment, more ground-based measurements are required using advanced equipment for better validation of satellite AOD data. This study suggests to develop a real-time air quality database supported by satellite data which can be utilized for effective implementation of environmental laws and policies in Pakistan.

\section{Acknowledgement}

The research data on the Validation of Aerosol Optical Depth Products over Pakistan was provided by NASA AERONET station. This data provided insight and expertise that greatly assisted in the research. We could identify different aspects and results related to this research.

\section{Conflict of Interest}

The authors declare that there is no conflict of interests regarding the publication of this manuscript.

\section{References}

[1] C.I. Davidson, R.F. Phalen, P.A. Solomon, Airborne particulate matter and human health: A review, Aerosol Science and Technology. 39(8) (2005) 737-749.

[2] F. Dominici et al., Fine particulate air pollution and hospital admission for cardiovascular and respiratory diseases, Jama. 295(10) (2006) 1127-1134.

[3] P.V. Hobbs, Aerosol-cloud-climate interactions, Vol. 54, Academic Press, 1993.

[4] K. Alam, T. Trautmann, T. Blaschke, Aerosol optical properties and radiative forcing over mega-city Karachi, Atmospheric Research. 101(3) (2011) 773-782.

[5] K. Alam et al., Aerosol size distribution and mass concentration measurements in various cities of Pakistan, Journal of Environmental Monitoring. 13(7) (2011) 1944-1952.

[6] K. Alam, S. Qureshi, T. Blaschke, Monitoring spatio-temporal aerosol patterns over Pakistan based on MODIS, TOMS and MISR satellite data and a HYSPLIT model, Atmospheric environment. 45(27) (2011) 4641-4651.

[7] V.A. Dutkiewicz et al., Black carbon aerosols in urban air in South Asia, Atmospheric Environment. 43(10) (2009) 1737-1744.

[8] B.M. Ghauri et al., Composition of aerosols and cloud water at a remote mountain site (2.8 kms) in Pakistan, Chemosphere, Glob Chang Sci. 3 (2001) 51-63.

[9] B. Ghauri, M. Salam, M.I. Mirza, An assessment of air-quality in Karachi, Pakistan, Environ. Monit. Assess. 32 (1994) 37-45.

[10] K. Alam et al., Monitoring spatio-temporal variations in aerosols and aerosol-cloud interactions over Pakistan using MODIS data, Advances in Space Research. 46(9) (2010) 1162-1176. 
[11] M. Ali et al., A study of aerosol properties over Lahore (Pakistan) by using AERONET data, Asia-Pacific Journal of Atmospheric Sciences. 50(2) (2014) 153-162.

[12] B.N. Holben et al., AERONET - A federated instrument network and data archive for aerosol characterization, Remote sensing of environment. 66(1) (1998) 1-16.

[13] B.N. Holben et al., AERONET - A federated instrument network and data archive for aerosol characterization, Remote Sensing of Environment. 66 (1998) 1-16.

[14] X. Jiang et al., Comparison of MISR aerosol optical thickness with AERONET measurements in Beijing metropolitan area, Remote Sensing of Environment. 107(1) (2007) 45-53.

[15] Y.J. Kaufman et al., The MODIS 2.1- $\mu \mathrm{m}$ channel-correlation with visible reflectance for use in remote sensing of aerosol, IEEE transactions on Geoscience and Remote Sensing. 35(5) (1997) 1286-1298.

[16] A.A. Kokhanovsky et al., Aerosol remote sensing over land: A comparison of satellite retrievals using different algorithms and instruments, Atmospheric Research. 85(3) (2007) 372-394.

[17] M.S. Wong et al., Validation of MODIS, MISR, OMI, and CALIPSO aerosol optical thickness using ground-based sunphotometers in Hong Kong, International journal of remote sensing. 34(3) (2013) 897-918.

[18] K.R. Knapp, Quantification of aerosol signal in GOES 8 visible imagery over the United States, Journal of Geophysical Research: Atmospheres. 107(D20) (2002).

[19] Z. Li et al., First observation-based estimates of cloud-free aerosol radiative forcing across China, Journal of Geophysical Research: Atmospheres. 115(D7) (2010).

[20] K. Alam et al., Aerosol optical and radiative properties during summer and winter seasons over Lahore and Karachi, Atmospheric Environment. 50 (2012) 234-245.

[21] K.F. Biswas, B.M.Ghauri, L. Husain, Gaseous and aerosol pollutants during fog and clear episodes in South Asian urban atmosphere, Atmospheric Environment. 42(33) (2008) 77757785.

[22] I.I. Chaudhri, The vegetation of Karachi, Vegetatio. 10(3-4) (1961) 229-246.

[23] S.A. Qadir, S.Z. Qureshi, M.A. Ahmed, A phytosociological survey of the Karachi University Campus, Plant Ecology. 13(6) (1966) 339-362.

[24] Information on https://aeronet.gsfc.nasa.gov/cgi-bin/webtool_aod_v3?stage=2\&place_code $=10 \&$ region $=$ Asia\&state $=$ Pakistan $\&$ submit $=$ Get + AERONET + Sites .

[25] C.L. Parkinson, Aqua: An Earth-observing satellite mission to examine water and other climate variables, IEEE Transactions on Geoscience and Remote Sensing. 41(2) (2003) 173183.

[26] D.J. Diner et al., MISR aerosol optical depth retrievals over southern Africa during the SAFARI-2000 dry season campaign, Geophys. Res. Lett. 28(6) (2001) 3127-3130.

[27] D.M. Winker, W.H. Hunt, M.J. McGill, Initial performance assessment of CALIOP, Geophysi. Res. Lett. 34(19) (2007) L19803.

[28] P.A.Roussos et al., Relations of environmental factors with the phenol content and oxidative enzyme activities of olive explants, Scientia horticulturae. 113(1) (2007) 100-102.

[29] A.S. Wali, B.H. Kabura, Correlation studies in tomato (Lycopersicon lycopersicum L. Karst) as affected by mulching and cultivar during the heat period in the Semi-Arid Region of Nigeria, International Letters of Natural Sciences. 15 (2014) 1-7.

[30] A.C. Rencher, G.B. Schaalje, Linear models in statistics, John Wiley \& Sons, 2008. 
[31] P.T.T. Ha et al., Development of new drought tolerant breeding lines for Vietnam using marker-assisted backcrossing, International Letters of Natural Sciences. 59 (2016) 1-13.

[32] P. Gupta et al., MODIS aerosol optical depth observations over urban areas in Pakistan: Quantity and quality of the data for air quality monitoring, Atmospheric Pollution Research. 4(1) (2013) 43-52.

[33] H. Bibi et al., Intercomparison of MODIS, MISR, OMI, and CALIPSO aerosol optical depth retrievals for four locations on the Indo-Gangetic plains and validation against AERONET data, Atmospheric Environment. 111 (2015) 113-126.

[34] D.J. Diner et al., Multi-angle Imaging SpectroRadiometer (MISR) instrument description and experiment overview, IEEE Transactions on Geoscience and Remote Sensing. 36(4) (1998) 1072-1087.

[35] R.A .Kahn et al., Satellite-derived aerosol optical depth over dark water from MISR and MODIS: Comparisons with AERONET and implications for climatological studies, Journal of Geophysical Research: Atmospheres. 112(18) (2007).

[36] M. Kroon et al., Ozone Monitoring Instrument geolocation verification, Journal of Geophysical Research. 113(15) (2008)

[37] C. Ahn, O. Torres, P.K. Bhartia, Comparison of ozone monitoring instrument UV aerosol products with aqua/moderate resolution imaging spectroradiometer and multiangle imaging spectroradiometer observations in 2006, Journal of Geophysical Research: Atmospheres. 113(16) (2008).

[38] D.M. Winker et al., Overview of the CALIPSO mission and CALIOP data processing algorithms, Journal of Atmospheric and Oceanic Technology. 26(11) (2009) 2310-2323.

[39] M.A. Ali, M. Assiri, R. Dambul, Seasonal Aerosol Optical Depth (AOD) variability using satellite data and its comparison over Saudi Arabia for the period 2002-2013, Aero. Air Qual. Res. 17 (2017) 1267-1280.

[40] M.A. Ali, M.E. Assiri, Spatio-temporal analysis of aerosol concentration over Saudi Arabia using satellite remote sensing techniques, Malaysian J. Society Space. 12 (2016) 1-11.

[41] M.J. Butt, M.E. Assiri, M.A. Ali, Assessment of AOD variability over Saudi Arabia using MODIS Deep Blue products, Environ. Poll. 231 (2017) 143-153.

[42] A. Rasheed et al., Measurement and analysis of fine particulate matter (PM2.5) in urban areas of Pakistan, Aerosol Air Qual. Res. 15 (2015) 426-439.

[43] H.A. Khwaja et al., An in-depth characterization of urban aerosols using electron microscopy and energy dispersive X-Ray analysis, CLEAN - Soil, Air, Water. 37(7) (2009) 544-554. 